\title{
Special issue: Working from home
}

In recent years, work from home (WFH) has become widely prevalent in many industries as the majority of the world was sent home due to the COVID-19 pandemic. This special issue dedicated to WFH will provide an extensive look into the unique opportunities and challenges these work environments present. While many may think that WFH is a unique paradigm that resulted purely from the COVID-19 pandemic, numerous companies have worked from home for years. The case study by Larry English provides insights into one example of how working from home can be successful, as they have been doing so for more than a decade. This case study sets up the broader context of the WFH modality. Other research [2-4] has provided insights into the ergonomic stressors and the necessity to accommodate workers at home. Further, WFH has especially unique environments that impact the visual strain of workers, relating to the lighting conditions $[5,6]$. WFH has also offered unique opportunities for certain occupations by allowing workers to do traditional inperson work through telework, oftentimes with little or no impact in service [10-12]. There also appears to be an impact on the work life-balance. It has also been found that these WFH work environments may have lasting impact on the health and well-being of the workers [7-10].

One profession that appears to have been particularly impacted by a transition to WFH is academicians $[13,14]$, leading to adverse well-being and burnout. Students have also shifted to having many courses online where they have had to adapt to learning in non-traditional work environments. They are oftentimes using laptops in non-traditional workspaces, and have limited resources to create safe and ergonomic workstations [15, 16]. With many schools, particularly universities, continuing online courses, students and professors will need to consider the work environments at home.
Although the pandemic will hopefully wind down in the near future and become an endemic, WFH and the accommodation of workers is likely here to stay as companies continue to shift to WFH or hybrid work [17]. A systems approach [18] will likely need to be utilized as workers will be in complex environments, potentially impacting worker well-being, stress, and burnout. While the COVID-19 pandemic has resulted in millions of employees working from home, other natural disasters [19], future pandemics, and corporate culture changes will ensure WFH is a mainstay in the future of work.

The special issue provides many insights into the complexity of working from home. While there is an opportunity to utilize WFH effectively, workers will need to be accommodated from an ergonomic and organizational perspective.

Kermit Davis and Susan Kotowski

\section{Note from the Editor-in-Chief}

I have eagerly looked forward to the publication of this special issue on work from home. My appreciation and gratitude are extended to Kermit Davis and Susan Kotowski for their dedication to making this important topic as a special issue of WORK a reality.

Karen Jacobs Editor-in-Chief, WORK

\section{References}

[1] English L. Centric Consulting case study: Culture is the key to remote work success. Work. 2022;71(2):295-98.

[2] Black NL, St-Onge S. Measuring pandemic home-work conditions to determine ergonomic recommendation relevance. Work. 2022;71(2):299-308.

[3] MacLean KFE, Neyedli HF, Dewis C, Frayne RJ. The role of at-home workstation ergonomics and gender on musculoskeletal pain. Work. 2022;71(2):309-18. 
[4] Kotowski SE, Davis KG, Gerding T. Almost a year in: Virtual offices remain an ergonomic trouble spot. Work. 2022;71(2):319-26.

[5] Saoji AA, Swathi PS, Raghavendra BR. Role of trataka in ameliorating visual strain and promoting psychological well-being during prolonged use of digital displays: A randomized controlled trial. Work. 2022;71(2):327-33.

[6] McKee C, Hedge A. Ergonomic lighting considerations for the home office workplace. Work. 2022;71(2):335-343.

[7] Pradoto H, Haryono S, Wahyuningsih SH. The role of work stress, organizational climate, and improving employee performance in the implementation of working from home. Work. 2022;71(2):345-355.

[8] Ahmadi F, Zandi S, Cetrez ÖA, Akhavan S. Job satisfaction and challenges of working from home at the time of COVID-19: A study in a Swedish academic setting. Work. 2022;71(2):357-370.

[9] Zalat M, Bolbol S. Telework benefits and associated health problems during the long COVID-19 era. Work. 2022;71(2):371-78

[10] Kumaresan A, Suganthirababu P, Srinivasan V, Chandhini YV, Divyalaxmi P, Alagesan J, Vishnuram S, Ramana K, Prathap L. Prevalence of burnout syndrome among work from home IT professionals during the COVID-19 pandemic. Work. 2022;71(2):379-384.

[11] Abbott-Gaffney CR, Gafni-Lachter L, Cason J, Sheaffer K, Harasink R, Donehower K, Jacobs K. Toward successful future use of telehealth in occupational therapy practice: What the COVID-19 rapid shift revealed. Work. 2022;71(2):385-394.
[12] El Kadri Filho F, Roberto de Lucca S. Telework during the COVID-19 pandemic: Ergonomic and psychosocial risks among Brazilian labor justice workers. Work. 2022;71(2):395-405.

[13] Kotowski SE, Davis KG, Barratt CL. Teachers feeling the burden of COVID-19: Impact on well-being, stress, and burnout. Work. 2022;71(2):407-15.

[14] Horton N, Jacobs K. How do remote working environments impact perceived work-related quality of life for academicians within the United States? Work. 2022;71(2): 417-21.

[15] Moslander D, Jacobs K. Efficacy of an ergonomics intervention for remote college students. Work. 2022;71(2):423-31.

[16] Kotowski SE, Davis KG. The virtual office: A perspective from college students. Work. 2022;71(2):433-40.

[17] Rampasso IS, Santana M, Serafim MP, Dibbern T, Rodrigues EA, Filho WL, Anholon R. Trends in remote work: A science mapping study. Work. 2022;71(2):441-50.

[18] Robertson MM, Lin J, Huang E, Schleifer L. Virtual office intervention effectiveness: A systems approach. Work. 2022;71(2):451-64.

[19] Sarnosky K, Benden M, Sansom G, Cizmas L, Regan AK. Impact of workplace displacement during a natural disaster on computer performance metrics: A 2-year interrupted time series analysis. Work. 2022;71(2):465-70. 